\title{
$\mathrm{FIS}$ 와 신뢰도를 이용한 레이저 내비게이션의 정밀도 향상
}

\section{Accuracy Improvement of Laser Navigation System using FIS and Reliability}

\author{
정은국 ${ }^{*}$ 김정민 ${ }^{\star *}$. 정경훈 ${ }^{*}$. 김성신 ${ }^{*+}$ \\ Eunkook Jung*, Jungmin Kim*, Kyunghoon Jung ${ }^{*}$ and Sungshin Kim ${ }^{* *+}$ \\ * 부산대학교 로봇협동과정 \\ ** 부산대학교 전자전기공학과
}

\begin{abstract}
요 약
본 논문은 FIS(fuzzy inference system)와 신뢰도를 이용한 레이저 내비게이션의 정밀도 향상에 관한 것이다. 레이저 내비 게이션은 무선 유도 장치로써 헤드가 $360^{\circ}$ 회전을 하며 벽에 부착된 반사체(reflector)를 읽어 $\mathrm{AGV}$ (automatic guided vehicle)의 위치를 측정하는 장치이다. 기존의 대표적인 유도 장치들의 타입은 유선 유도 방식이다. 이들은 정밀도가 매우 높고 반응속도가 빠르기 때문에 대부분의 현장에서는 이들을 채택하고 있다. 하지만, 이들 센서는 바닥 밑 1 인치 안에 설 치하거나 바닥에 심어야하기 때문에 설치비용은 매우 높고 유지 보수가 어렵다. 이러한 문제를 해결하기 위해서 레이저 내 비게이션이 개발되었다. 이것은 바닥 시공 하는 것이 필요 없고 설치비용이 최소화되며 배치(layout) 변경이 쉽다. 하지만 외란에 영향을 많이 받아 데이터의 손실·손상이 크고 반응속도가 느리기 때문에 안전이 최우선인 산업현장에 사용이 어렵 다. 이에 본 논문에서는 레이저 내비게이션의 정밀도 향상에 관한 연구를 하였다. 제안된 방법은 레이저 내비게이션의 특 성을 분석하여 FIS를 통해 위치측정 정밀도의 신뢰도를 계산한 후에 이를 통해 레이저 내비게이션의 정밀도를 보정하는 방법이다. 본 논문에서는 실험을 위해서 직접 설계한 $\mathrm{AGV}$ 를 이용하였으며, 레이저 내비게이션의 위치와 레이저 내비게이 션의 신뢰도를 통해 보정된 위치를 제안된 방법과 비교 하였다. 실험 결과, FIS를 신뢰도로 보정한 결과가 다른 방법들에 비해 약 $50 \%$ 성능이 향상됨을 확인하였다.
\end{abstract}

키워드 : 퍼지 추론 시스템, 신뢰도, 레이저 내비게이션, 위치측정, 유도 시스템

\begin{abstract}
This paper presents to study the accuracy improvement of the laser navigation using FIS(fuzzy inference system) and the reliability. As wireless guidance system, the top-mounted laser with the laser navigation can rotate $360^{\circ}$ with phototransistor or other optical sensors that read the return signal from reflectors mounted at the perimeter of the workspace. The type of major existing guidance systems is a wire guidance system. Because they have high accuracy and fast response time, they are used to most industries. However, their installation cost is very expensive and maintenance is very difficult because their sensors are placed approximately 1 inch below the ground or embedded in the floor. To solve those problems, the laser navigation was developed as a wire guidance system. It does not need to reconstruct a floor or ground. And it can reduce costs of installation and maintenance because changing the layout is easy. However, it is difficult to apply to an industrial field because it is easily affected by disturbances which cause loss and damage of data, and has slow respond time. Therefore, we study the accuracy improvement of the laser navigation. The proposed method is a correction method using reliability of the laser navigation. here, reliability is calculated by FIS which is designed with the analyzed characteristics of the laser navigation. For performance comparison, we use original position data form the laser navigation and position data corrected by original reliability from the laser navigation. In experimental result, we verified that the performance of the proposed method compared the others is improved by about $50 \%$ or more.
\end{abstract}

Key Words : fuzzy inference system, reliability, laser navigation, localization, guidance system

\section{1. 서 론}

접수일자 : 2011년 3월 11일

완료일자 : 2011년 5월 30일

+ Corresponding Author : sskim@pusan.ac.kr

이 논문 또는 저서는 2011년 교육과학기술부로부터 지

원받아 수행된 연구임

(지역점연구단육성사업/차세대물류IT기술연구사업단)
최근, $\mathrm{AGV}$ 에 대한 관심이 높아지며 유도 장치에 대한 연구가 활발히 이루어지고 있다. 유도 기술은 $\mathrm{AGV}$ 의 위치 를 계측하기 위한 위치측정과 목표 위치로 이동하기 위한 주행제어 기술을 함께 지칭하는 말로써, 그것의 성능에 따 라 $\mathrm{AGV}$ 의 전체적인 성능이 좌우되게 된다[1-3]. 
위치측정 성능 향상에 관해 가장 많이 연구되고 있는 분 야는 최적 예측(optimal estimation)이다. 이는 일정 조건 속에서 일어나는 근거(reasonable)를 기반으로 하는 명제 (thesis)를 확률적으로 추정하는 것이다. 즉, 예측이 관찰 또 는 관측(observation)과 무관하지 않다는 것이다. 이를 기반 으로 개발된 대표적인 기법들로는 $\mathrm{EKF}$ (extended Kalman filter), UKF(unscented Kalman filter), $\mathrm{PF}$ (particle filter) 등이 있다[4-6]. 이들은 확률적인 잡음을 가진 하나의 시스 템이 시간에 따른 변화를 예측(prediction) 할 수 있도록 관 측을 통해 갱신(update)하는 기법들이다. 이러한 기법들은 시스템의 잡음 필터에 뛰어난 성능을 보이지만 시스템의 드 리프트(drift) 현상이나 센서 특성에 따른 알지 못하는 오차 에 대해서는 무방비이다[7-10]. 이에, 본 논문은 최적 예측 기법에 적용 전에 알 수 없는 오차를 해결하기 위해, 레이 저 내비게이션의 특성을 분석하여 FIS를 통해 위치측정 정 밀도의 신뢰도를 계산하고 이를 통해 레이저 내비게이션의 정밀도를 보정하는 방법에 관해 연구하였다.

본 논문의 구성은 다음과 같다. 2 장과 3 장과에서는 실험 에 사용된 계측 시스템과 센서 분석 내용을 설명하고, 4장 에서는 FIS를 이용한 신뢰도 계산과 보정 방법에 대해 이 야기 한다. 5장에서는 성능 실험 및 결과에 대해 다루고, 마 지막 6장에서는 결론 및 향후 연구과제에 대하여 기술한다.

\section{2. 계측 시스템}

\section{1 테스트용 AGV}

실험을 위해, $\mathrm{AGV}$ 전문 업체인 아티스(ATIS) 기연(주)와 함께 $\mathrm{AGV}$ 를 직접 설계하였다. 제작된 $\mathrm{AGV}$ 는 그림 1 과 같 다.

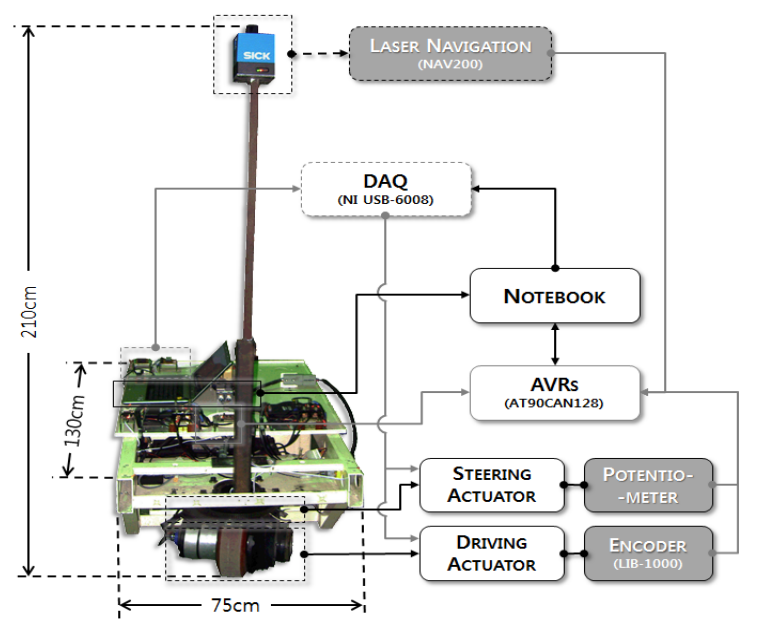

그림 1. 테스트용 $\mathrm{AGV}$

Fig. 1. AGV for test

제작된 $\mathrm{AGV}$ 는 시제품 개발 전의 테스트용으로 레이저 유도 $\mathrm{AGV}$ 의 빠른 개발을 위해서 노트북을 주 제어기로 사 용하였다. 그 크기는 $130 \times 75 \times 210 \mathrm{~cm}$ 이며, 주행과 조향 이 같은 위치에서 이루어지는 차축 구동 방식의 구동부를 가졌다. 또한, 차축 구동부의 조향 각을 제어하기 위해서 가 변 저항(potentiometer)을 설치하였으며, 주행 속도를 제어 하기 위해서 엔코더를 설치하였다.

\section{2 기구학}

실험에 사용된 $\mathrm{AGV}$ 는 리치식(reach type) 지게차로 차 축 구동부를 가진다. 그림 2 는 실험에 사용된 $\mathrm{AGV}$ 의 기구 학 모델을 나타낸 것이며, 절대좌표계 $O-X-Y$ 와 상대좌표 계 $O^{-} x-y$ 를 보여준다.

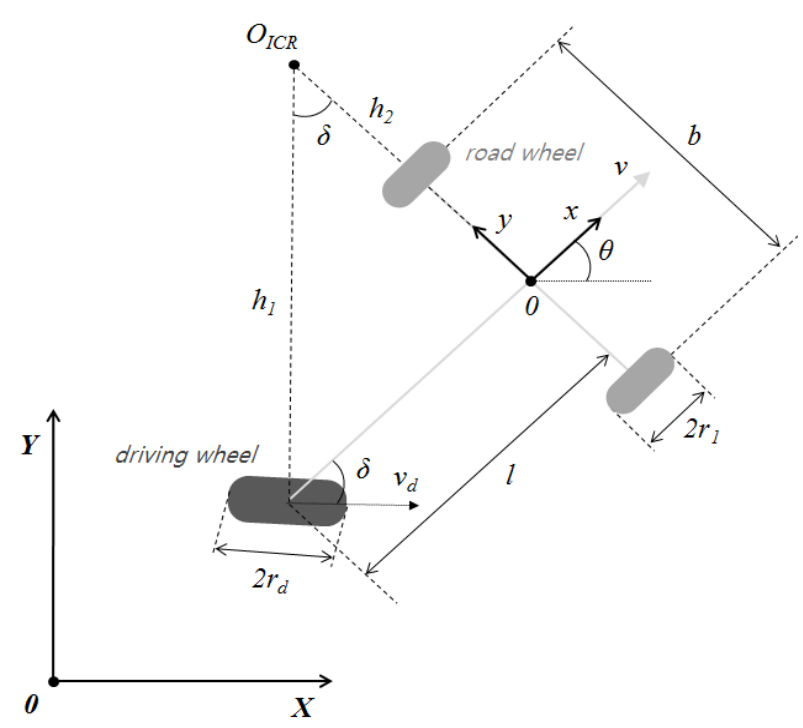

그림 2. $\mathrm{AGV}$ 의 기구학

Fig. 2. Kinematics model of AGV

위 그림에서 $O_{I C R}$ 은 $\mathrm{AGV}$ 가 곡선 주행할 때의 회전중심 축을 나타내며, $h_{1}$ 은 주행 바퀴의 중심과의 $O_{I C R}$ 의 거리를 나타낸다. 여기서, $h_{1}$ 은 주행 바퀴의 조향 각도와 주행 바퀴 의 중심과 보조 바퀴의 중간 간에 길이에 의해 식 (1)과 같 이 계산된다.

$$
h_{1}=\frac{l}{\sin \delta}
$$

여기서, $l$ 은 주행 바퀴의 중심과 보조 바퀴의 중심 간에 길이를 나타낸다. 바퀴가 바닥에서 회전하는 순간부터 바퀴 의 선속도가 지면속도와 같고 미끄러짐이 없을 때, 주행 바 퀴의 각도 변화량 $\dot{\delta}$ 은 식 (1)에서 계산된 $h_{1}$ 을 이용하여 다 음과 같이 계산한다.

$$
\dot{\delta}=\frac{v_{d}}{h_{1}}=\frac{v}{h_{1} \cos \delta}
$$

여기서, $v_{d}$ 는 주행 바퀴의 선속도를 의미하며, 이는 다음 식과 같다.

$$
v_{d}=r_{d} w_{d}
$$

여기서, $r_{d}$ 와 $w_{d}$ 는 각각 주행 바퀴의 반지름과 각속도를 나타낸다. 최종적인 $\mathrm{AGV}$ 의 좌표 값과 주행 방향각은 다음 식과 같이 구할 수 있다.

$$
\begin{gathered}
\dot{X}=v \cos \theta=r_{d} w_{d} \cos \theta \\
\dot{Y}=v \sin \theta=r_{d} w_{d} \sin \theta \\
\dot{\theta}=\frac{r_{d} w_{d} \sin \delta}{l}
\end{gathered}
$$




\section{3. 센서 분석}

레이저 내비게이션을 사용하기 위해서는 작업장에 반사 체 설치가 필요하다. 이는 레이저 내비게이션의 헤더가 $360^{\circ}$ 회전하며 레이저를 보내고 받는 속도를 통해 반사율 계산하기 때문이다. 이 때, 반사체를 설치하는 이유는 이미 설치된 반사체의 위치를 알고 있으면 반사율과 반사체의 위 치를 통해 위치를 계산할 수 있기 때문이다. 표 1 은 사용된 레이저 내비게이션의 주요 사양을 보여 준다.

표 1. 레이저 내비게이션의 주요 사양

Table 1. Major specifications of laser navigation

\begin{tabular}{c|l}
\hline Item & \multicolumn{1}{|c}{ Specification } \\
\hline \hline \multirow{4}{*}{$\begin{array}{c}\text { Laser navigation } \\
\text { (NAV200) }\end{array}$} & power supply: $24 \mathrm{~V}$ \\
\cline { 2 - 2 } & accuracy: $\pm 0.4 \mathrm{~mm} \sim \pm 25 \mathrm{~mm}$ \\
\cline { 2 - 2 } & scanning frequency: $8 \mathrm{~Hz}$ \\
\cline { 2 - 2 } & operating range: $1.2^{\sim} 28.5 \mathrm{~m}$ \\
\cline { 2 - 2 } & angular resolution: $0.1^{\circ}$ \\
\hline
\end{tabular}

레이저 내비게이션은 사용된 반사체의 사양과 개수에 따 라 정밀도가 달라진다. 사양 명세서(specification)에 따르면 레이저 내비게이션은 최대 $28.5 \mathrm{~m}$ 거리까지 반사체를 인식 할 수 있으며, 정지 정밀도는 $\pm 0.4 \mathrm{~mm} \sim \pm 25 \mathrm{~mm}$ 이다. 이는 정지하고 있을 때의 정밀도이며, 주행 중에는 더 많은 오차 를 발생시킨다. 하지만 레이저 내비게이션은 전역 위치측정 센서로 절대 위치를 계측하기 때문에 오차는 누적되지 않는 다. 센서 분석을 위해 사용된 실험 공간과 반사체의 정보는 다음 그림과 같다.

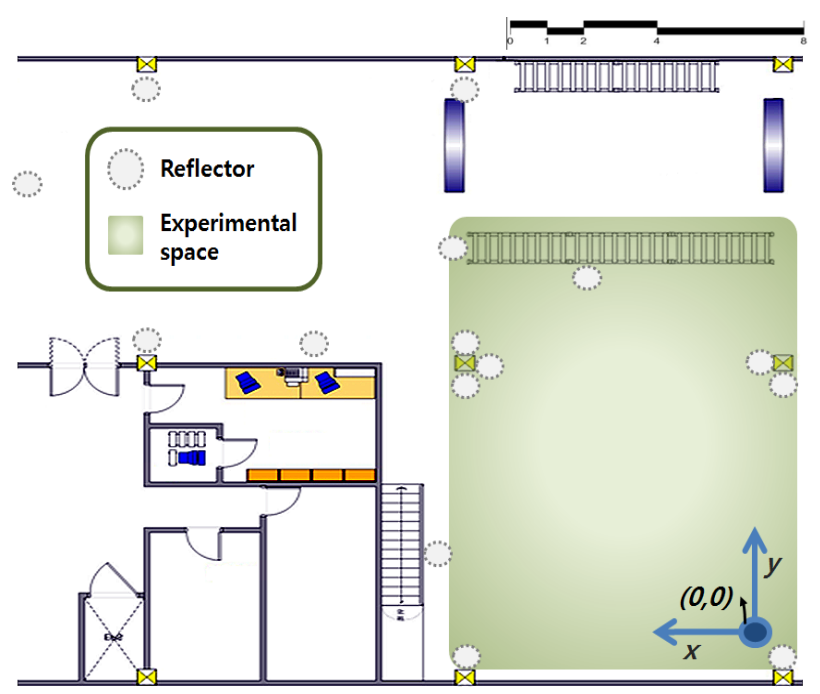

그림 3. 실험 공간과 반사체의 정보

Fig. 3. Experimental environment and information of reflector

사용된 반사체는 반사율을 극대화하기 위해 지름이 $9 \mathrm{~cm}$ 에 높이 $80 \mathrm{~cm}$ 높이인 원통에 부착하여 벽에 15 개를 설치 하였다. 반사체가 설치된 작업 공간의 크기는 $20 \mathrm{~m} \times 15 \mathrm{~m}$ 이고, 주로 사용된 실험 공간의 크기는 $8.4 \mathrm{~m} \times 11 \mathrm{~m}$ 이다.
센서 분석하기 위해, 조향 각과 주행 속도에 따른 위치측 정 오차를 계측하였다. 실험에 사용된 주행 속도는 $24 \mathrm{~cm} / \mathrm{s}$, $36 \mathrm{~cm} / \mathrm{s}, 48 \mathrm{~cm} / \mathrm{s}$ 이고, 사용된 조향 각은 $60^{\circ}, 45^{\circ}, 30^{\circ}$ 이다. 이는 사용된 $\mathrm{AGV}$ 의 최대·최소 조향 각이 $-80^{\circ} 80^{\circ}$ 이고 레 이저 내비게이션이 $\mathrm{AGV}$ 의 가운데 위치하고 있기 때문에 \pm 는 의미가 없었다. 또한, 조향 각이 $30^{\circ}$ 이하에서는 회전이 너무 크고, $60^{\circ}$ 이상일 때는 거의 제자리 회전이기 때문에 속도에 따라 넘어질 위험에 의해 천천히 달려야 한다. 실험 은 각 실험마다 10 바퀴를 주행하였다. 각 주행 속도와 조향 각에 따른 결과는 다음 표와 같다.

표 2. 주행 속도와 조향 각에 따른 거리 오차 $(\mathrm{mm})$ Table 2. Distance error due to speed and steering $(\mathrm{mm})$

\begin{tabular}{|c|c|c|c|c|c|c|}
\hline$\#$ & 속도 & 조향각 & RMSE & conv. & $\max$ & $\min$. \\
\hline 1 & \multirow{3}{*}{$24 \mathrm{~cm} / \mathrm{s}$} & $60^{\circ}$ & 19.35 & 307.63 & 28.03 & -40.65 \\
\hline 2 & & $45^{\circ}$ & 17.88 & 247.84 & 26.00 & -40.94 \\
\hline 3 & & $30^{\circ}$ & 13.09 & 141.38 & 25.03 & -28.89 \\
\hline 4 & \multirow{3}{*}{$36 \mathrm{~cm} / \mathrm{s}$} & $60^{\circ}$ & 25.83 & 648.41 & 42.31 & -48.09 \\
\hline 5 & & $45^{\circ}$ & 18.90 & 355.53 & 33.16 & -47.05 \\
\hline 6 & & $30^{\circ}$ & 18.65 & 349.68 & 34.08 & -48.33 \\
\hline 7 & \multirow{3}{*}{$48 \mathrm{~cm} / \mathrm{s}$} & $60^{\circ}$ & 27.04 & 710.99 & 35.35 & -66.03 \\
\hline 8 & & $45^{\circ}$ & 24.78 & 617.63 & 39.59 & -49.82 \\
\hline 9 & & $30^{\circ}$ & 20.40 & 358.93 & 40.74 & -38.95 \\
\hline
\end{tabular}

위 표를 보면, 주행 속도와 조향 각이 커질수록 오차 RMSE 가 커지는 것을 확인 할 수 있다. 조향 각에 따른 각 위치측정 실험들의 오차 박스 플롯(box plot)은 다음 그림과 같다.

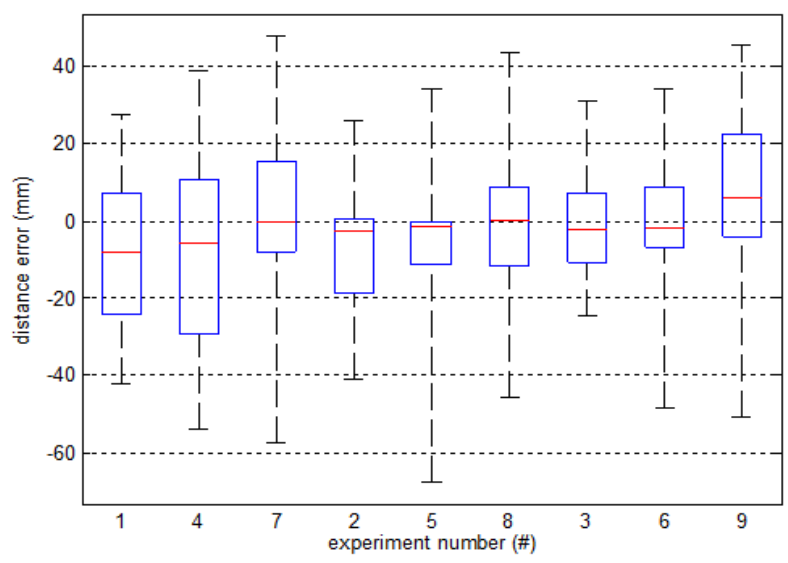

그림 4. 각 실험들의 박스 플롯

Fig. 4. Box plot of each experiment

그림 4에서 수염(whisker)은 최대·최소 오차값을 의미하 고, 실험 번호는 표 2 의 실험 번호에 매칭 된다. 최대·최소 오차 값의 변화를 보면, 주행 속도에 영향을 많이 받는 것 처럼 보인다. 하지만, 1 사분위수(lower percentile)와 3 사분 위수(upper percentile)를 살펴보면, 실제로는 조향 각에 영 향을 더 많이 받는 것을 알 수 있다. 이는 레이저 내비게이 션의 헤더가 $360^{\circ}$ 회전하면서 반사체를 읽기 때문이다. 


\section{FIS를 이용한 신뢰도 계산과 보정}

\subsection{FIS를 이용한 신뢰도 계산}

3장에서 언급한 센서 분석 내용을 토대로 $\mathrm{FIS}$ 를 설계하 였다. 입력은 각속도와 선속도이며, 2장에서 언급한 기구학 을 토대로 가변 저항 값과 엔코더의 주행 거리를 측정하여 계산하였다. 입력에 대한 퍼지 소속도함수(membership function)는 다음 그림과 같다.
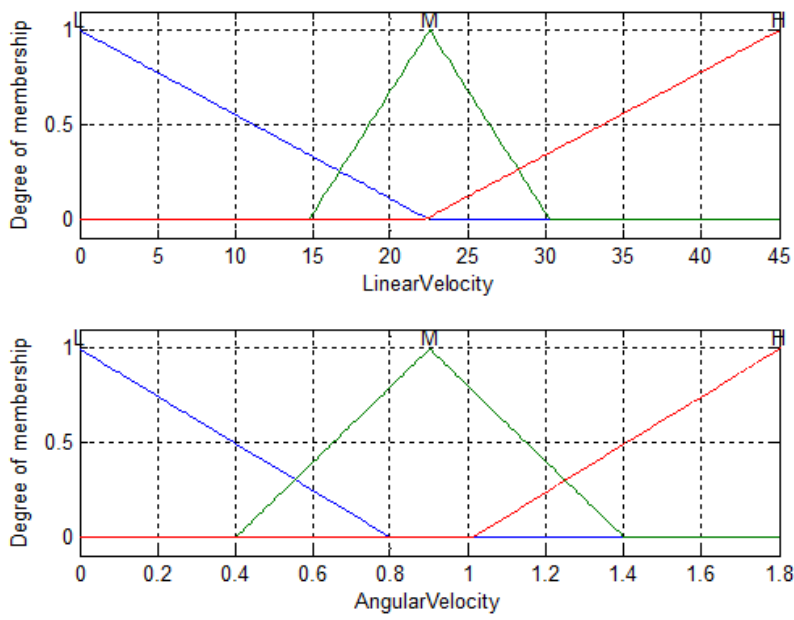

그림 5. 입력 소속도 함수들

Fig. 5. Input membership functions

분석된 오차들은 선형 근사화 시켜 삼각함수로 구성하였 다. 출력 소속도 함수는 레이저 내비게이션의 신뢰도 값이 며, 구성된 입력에 대한 출력은 다음 그림과 같다.

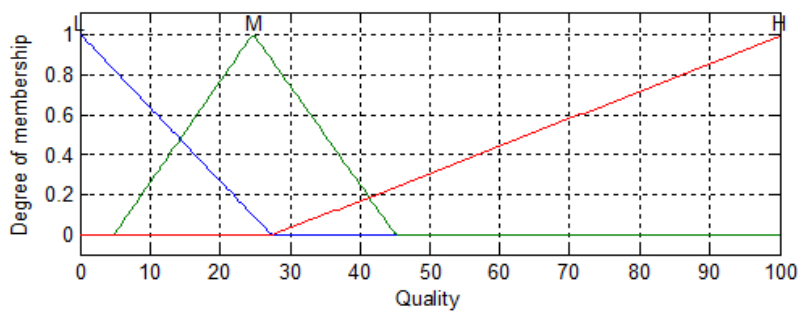

그림 6. 출력 소속도 함수

Fig. 6. Output membership function

신뢰도에 대한 기준들은 실제 레이저 내비게이션에서 제 공하는 신뢰도를 기준으로 만들었다. 사용된 퍼지 룰(rule) 은 다음 표와 같다.

표 3. 사용된 퍼지 룰

Table 3. Used fuzzy rule

\begin{tabular}{|c|c|c|c|c|}
\hline & \multicolumn{4}{|c|}{ Liner velocity } \\
\hline \multirow{4}{*}{ 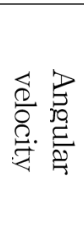 } & & $\mathrm{L}$ & M & $\mathrm{H}$ \\
\hline & $\mathrm{L}$ & $\mathrm{H}$ & M & $\mathrm{L}$ \\
\hline & $\mathrm{M}$ & $\mathrm{M}$ & M & $\mathrm{L}$ \\
\hline & $\mathrm{H}$ & $\mathrm{L}$ & $\mathrm{L}$ & $\mathrm{L}$ \\
\hline
\end{tabular}

최종적으로 나오는 FIS의 출력의 총 표면(surface)는 다 음 그림과 같다.

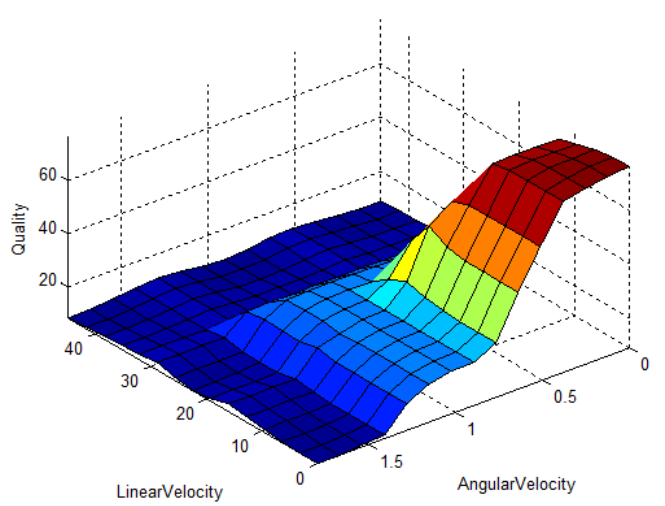

그림 7. 출력 표면

Fig. 7. Output surface

\section{2 신뢰도를 통한 위치 보정 방법}

신뢰도는 시스템의 드리프트(drift) 현상이나 센서 특성 에 따른 알지 못하는 오차를 보정하기 위해 사용된다. 본 논문은 최적 예측 기법의 오차 공분산을 조절하기 위한 선 행 연구이기 때문에 구해진 신뢰도의 성능을 분석하기 위해 신뢰도를 통해 위치측정을 간단한 방법으로 보정하였다. 보 정 방법은 다음 그림과 같다.

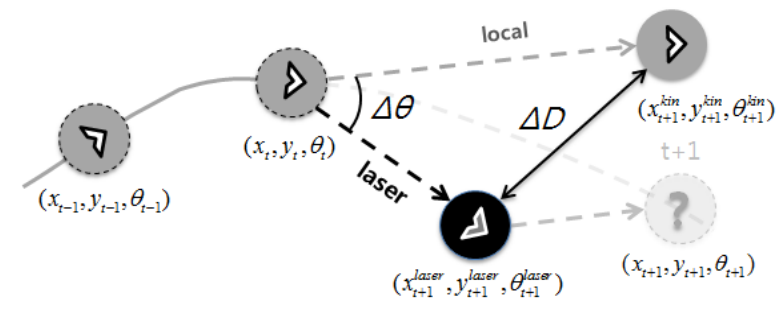

그림 8. 보정 방법

Fig. 8. Correction method

$\mathrm{t}$ 시간에서 $\mathrm{t}+1$ 시간에 $\mathrm{AGV}$ 가 화살 방향의 각도로 주행 할 때에 $\mathrm{AGV}$ 위치는 기구학(local)과 레이저 내비게이션 (laser) 두 방법으로 위치를 계산할 수 있다. 이 때, 기구학 으로 계산된 위치와 레이저 내비게이션의 위치의 각도 차 $\Delta$ $\Theta$ 와 거리 차 $\Delta D$ 를 계산하여 다음 식과 같이 보정한다.

$$
\begin{aligned}
& x_{k+1}=x_{t+1}^{\text {laser }}+\text { Quality } \times \Delta D \times \cos (\Delta \theta) \\
& y_{k+1}=y_{t+1}^{\text {laser }}+\text { Quality } \times \Delta D \times \sin (\Delta \theta)
\end{aligned}
$$

여기서, Quality는 4.1절에서 설계한 FIS의 출력으로 나 온 신뢰도 값이다.

\section{4. 실험 결과}

실험 환경과 방법은 3 장에서 언급한 것과 같다. FIS를 통 해 계산된 신뢰도의 성능 비교를 위해, 제안된 신뢰도를 통 해 보정된 위치 데이터(1)와 레이저 내비게이션이 제공하 는 신뢰도를 통해 보정된 위치 데이터(2) 그리고 레이저 내비게이션의 원 위치 데이터(3) 3 개의 성능을 비교하였다. 
각 실험들(1), (2), (3))들에 대한 전체 실험 결과의 $\mathrm{RMSE}$ 는 다음과 같다.

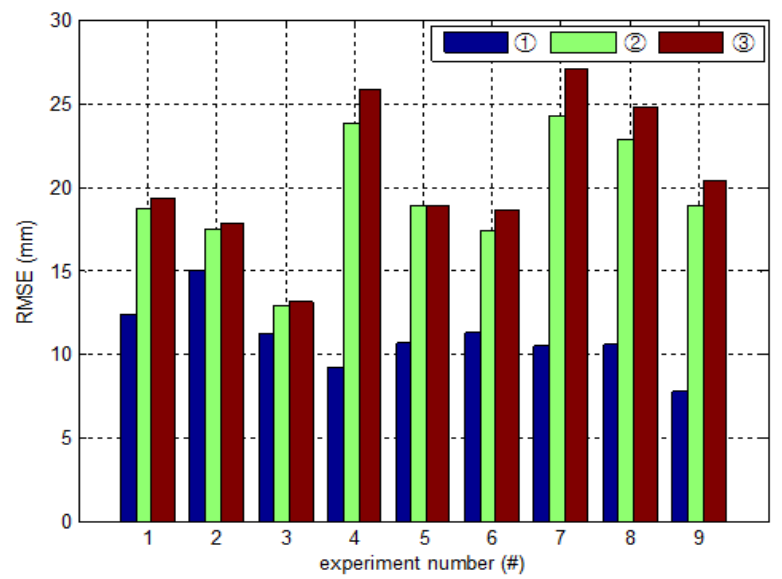

그림 9. 실험 결과들의 RMSE

Fig. 9. RMSE of experimental results

전체 실험(1), (2), (3))의 RMSE 평균은 각각 $10.71 \mathrm{~mm}$, $19.48 \mathrm{~mm}, 20.67 \mathrm{~mm}$ 를 가졌고, 전체적으로 (1) 실험의 정밀 도가 높은 것을 확인 할 수 있다. 다음 그림들은 5번 실험 인 $36 \mathrm{~cm} / \mathrm{s}$ 속도와 $45^{\circ}$ 의 조향 각을 가질 때에 위치측정 결 과를 보여준다. 여기서는 총 10 바퀴 중 첫 번째 바퀴의 결 과이고, 그림 10 는 (1), (2)의 위치와 오차 결과를 보여준다.
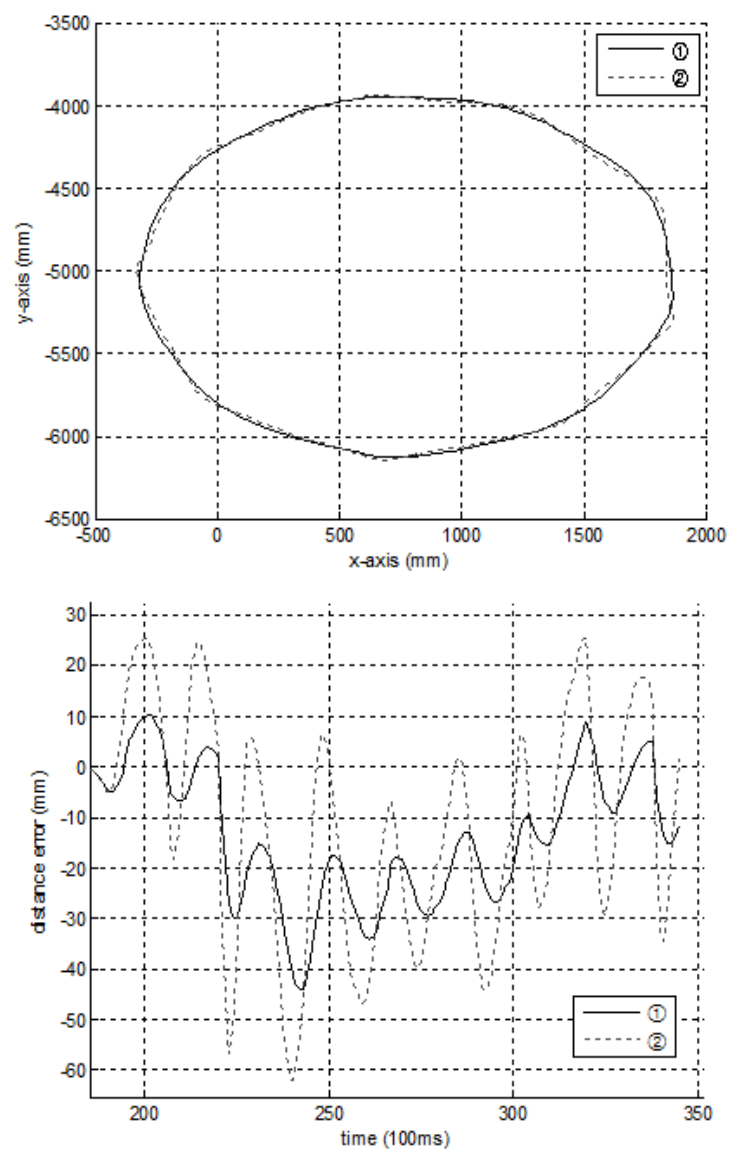

그림 10. (1)과 (2)의 위치와 오차 결과

Fig. 10. Results of position and error of (1) and (2)
위치 결과는 조향 각이 고정된 주행을 하고 있으므로 원 을 그리는 결과가 좋은 결과이다. 오차 결과를 보게 되면 오차가 전체적으로 쏠리는 현상을 확인할 수 있는 데, 이는 오차를 계산하기 위한 레퍼런스 값 때문이다. 이는 실제 환 경과 모델링 사이에 완벽한 실험환경을 구축할 수 없기 때 문에 발생되는 현상이다. 즉, 모델링이 시스템과 완벽할 수 없고 완벽히 평평한 바닥의 실험환경을 구축할 수 없기 때 문이다. 전체 실험 결과의 최대·최소 오차는 다음과 같다.

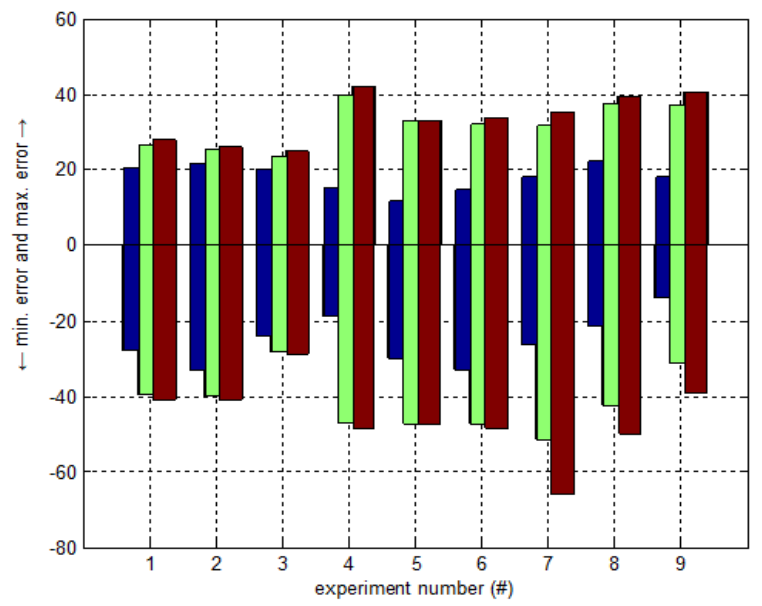

그림 11. 실험 결과들의 최대·최소 오차

Fig. 11. Max. and min. error of experimental results

위 그림에서 알 수 있듯이, (3) 실험과 (2) 실험에서 위치 측정 정밀도는 각 $\pm 67.12 \mathrm{~mm}, \pm 52.69 \mathrm{~mm}$ 를 가지는 것을 확 인하였다. 그리고 FIS의 신뢰도를 이용한 방법인 (1) 실험의 정밀도는 $\pm 32.15 \mathrm{~mm}$ 로 레이저 내비게이션의 원래 위치측정 결과인 (3) 실험에 비해 약 $50 \%$ 이상의 성능 향상을 확인 할 수 있었다.

\section{5. 결 론}

본 논문은 레이저 내비게이션의 성능 향상을 위한 $\mathrm{FIS}$ 를 이용한 신뢰도 계산과 보정 방법 관한 것이었다. 실험을 위 해 직접 설계한 $\mathrm{AGV}$ 를 이용하였으며, 이를 통해 센서를 분석하였다. 분석 결과, 레이저 내비게이션의 정밀도는 선속 도와 각속도 따라 영향을 크게 받는 다는 사실을 확인하였 고 선속도와 각속도에 따른 오차를 계산하였다. 또한, 각속 도가 선속도보다 레이저 내비게이션의 정밀도에 영향을 더 크게 미치는 것을 확인하였다. 분석된 선속도와 각속도에 따른 오차를 이용하여 FIS를 설계하였다. 본 논문은 최적 예측 기법의 오차 공분산을 조절하기 위한 선행 연구이기 때문에 구해진 신뢰도의 성능을 분석하기 위해서 신뢰도를 통한 위치 보정 방법을 이야기 하였다. FIS를 통한 신뢰도 의 성능을 분석하기 위해, FIS에서 나온 신뢰도를 통해 보 정된 위치 데이터와 레이저 내비게이션이 제공하는 신뢰도 를 통해 보정된 위치 데이터와 레이저 내비게이션의 원 위 치 데이터 3 개의 성능을 비교하였다 실험 결과, $\mathrm{FIS}$ 를 통한 신뢰도가 레이저 내비게이션이 제공하는 신뢰도보다 높은 성능을 확인 할 수 있었으며, 레이저 내비게이션의 원래 위 치측정 결과에 비해 FIS에서 나온 신뢰도 값을 통해 보정 된 위치측정 성능이 약 $50 \%$ 향상된 것을 확인할 수 있었다. 


\section{참 고 문 헌}

[1] J. Borenstein, "The OmniMate: A Guidewire and Beacon-free AGV for highly Reconfigurable Applications," International Journal of Production Research, vol. 38, no. 9, pp. 1993-2010, 2000.

[2] I. A. Vis, "Survey of Research in the Design and Control of Automated Guided Vehicle Systems," European Journal of Operational Research, vol. 170, no. 3, pp. 677-709, 2006.

[3] C. Y. Chan, "A System Review of Magnetic Sensing System for Ground Vehicle Control and Guidance," California PATH Research Report, UCB-ITS-PRR-2002-20, 2002.

[4] L. Jetto, S. Longhi, and G. Venturini "Development and Experimental Validation of an Adaptive Extended Kalman Filter for the Localization of Mobile Robots," IEEE Transactions on Robotics and Automation, vol 15, no 5, pp. 219-229. 1999.

[5] E. A. Wan and R. van der Merwe, "The Unscented Kalman Filter for Nonlinear Estimation," in Proc. of IEEE Symposium 2000 (AS-SPCC), Lake Louise, Alberta, Canada, Oct. 2000.

[6] D. Lee and K. T. Alfriend. "Precise Real-Time Orbit Estimation Using The Unscented Kalman Filter," Advances in the Astronautical Sciences, vol. 114, no. 3, pp. 1853-1872, 2003.

[7] Jinwoo Choi, "Robust Sonar Feature Detection for the SLAM of Mobile Robot," IEEE/RSJ International Conference, pp.3415-3420, Aug. 2005.

[8] H. Durrant-Whyle and T. bailey, "simultaneous Localization and Mapping: Part I," IEEE Robotics and Automation Magazine, vol. 13, pp.99-108, 2006.

[9] J. A. Castellanos, R. Martinez-Cantin, J. D. Tardos and J. Neira, "Robocentric map joining: Improving the Consistency of EKF-SLAM," Robotics and Autonomous Systems, vol. 55, issue 1, pp 21-29, 2007.

[10] Howie Choset, Keiji Nagatani, "Topological Simultaneous Locaization and Mapping(SLAM): Toward Exact Locaization Without Explicit Localization," IEEE Transactions on Robotics and Automation, vol 17, no. 2, pp 125-137, Apr. 2001.

\section{저 자 소 개}

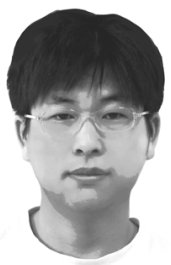

정은국(Eunkook Jung)

2010년 : 신라대학교 자동차기계전자공학부 (공학사)

2010년 현재 : 부산대학교 로봇협동과정 석사 과정

관심분야 : 지능 시스템, 지능형 로봇

E-mail : silverkook@pusan.ac.kr

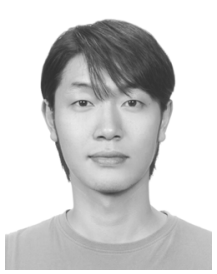

김정민(Jungmin Kim)

2006년 : 신라대학교 컴퓨터공학과(공학사) 2008년 : 부산대학교 전기공학과(공학석사) 2008년 현재 : 동대학원 전자전기공학과 박사과정

관심분야 : 신호처리, 지능 시스템, 지능형 로봇

E-mail :kjm16@pusan.ac.kr

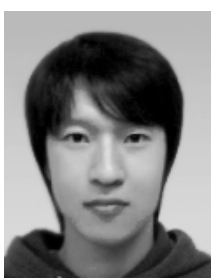

정경훈(Kyunghoon Jung)

2008년 : 신라대학교 컴퓨터공학과(공학사) 2009년 현재 : 부산대학교 로봇협동과정 석사 과정

관심분야 : 신호처리, 지능제어, 지능형 로봇

E-mail : hooraring@pusan.ac.kr

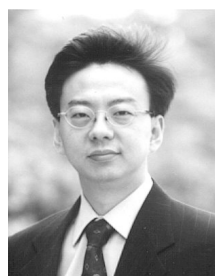

김성신(Sungshin Kim)

1986년 : 연세대학교 전기공학과(공학석사)

1996년 : Georgia Inst. of Technology, 전기및컴퓨터공학부(공학박사)

1998년 현재 : 부산대학교 전자전기공학부 교수

관심분야 : 지능 시스템, 지능형 로봇, 고장 예측 및 진단

Phone : +82-51-510-2374

Fax : $+82-51-513-0212$

E-mail :sskim@pusan.ac.kr 